\title{
Molecular cloning and expression of a novel trehalose synthase gene from Enterobacter hormaechei Ming Yue ${ }^{1}$, Xiu Li Wu${ }^{1}$, Wei Na Gong ${ }^{2}$ and Hong Biao Ding*1
}

\author{
Address: ${ }^{1}$ Feed Research Institute, Chinese Academy of Agricultural Sciences, Beijing 100081, PR China and ${ }^{2}$ Institute of Plant Protection, Chinese \\ Academy of Agricultural Sciences, Beijing 100094, PR China \\ Email: Ming Yue - yuemingrock@yahoo.com; Xiu Li Wu - suweh12986@163.com; Wei Na Gong - gongweina1118@yahoo.com.cn; \\ Hong Biao Ding* - dinghongbiao@mail.caas.net.cn \\ * Corresponding author
}

Published: 12 June 2009

Microbial Cell Factories 2009, 8:34 doi:10.II86/1475-2859-8-34
Received: 20 January 2009

Accepted: 12 June 2009

This article is available from: http://www.microbialcellfactories.com/content/8/I/34

(c) 2009 Yue et al; licensee BioMed Central Ltd.

This is an Open Access article distributed under the terms of the Creative Commons Attribution License (http://creativecommons.org/licenses/by/2.0), which permits unrestricted use, distribution, and reproduction in any medium, provided the original work is properly cited.

\begin{abstract}
Background: Trehalose synthase (TreS) which converts maltose to trehalose is considered to be a potential biocatalyst for trehalose production. This enzymatic process has the advantage of simple reaction and employs an inexpensive substrate. Therefore, new TreS producing bacteria with suitable enzyme properties are expected to be isolated from extreme environment.

Results: Six TreS producing strains were isolated from a specimen obtained from soil of the Tibetan Plateau using degenerate PCR. A novel treS gene from Enterobacter hormaechei was amplified using thermal asymmetric interlaced PCR. The gene contained a 1626 bp open reading frame encoding 54I amino acids. The gene was expressed in Escherichia coli, and the recombinant TreS was purified and characterized. The purified TreS had a molecular mass of $65 \mathrm{kDa}$ and an activity of $18.5 \mathrm{U} / \mathrm{mg}$. The optimum temperature and $\mathrm{pH}$ for the converting reaction were $37^{\circ} \mathrm{C}$ and 6, respectively. $\mathrm{Hg}^{2+}, \mathrm{Zn}^{2+}, \mathrm{Cu}^{2+}$ and SDS inhibited the enzyme activity at different levels whereas $\mathrm{Mn}^{2+}$ showed an enhancing effect by $10 \%$.

Conclusion: In this study, several TreS producing strains were screened from a source of soil bacteria. The characterization of the recombinant TreS of Enterobacter hormaechei suggested its potential application. Consequently, a strategy for isolation of TreS producing strains and cloning of novel treS genes from natural sources was demonstrated.
\end{abstract}

\section{Background}

Trehalose, a non-reducing disaccharide with two glucoses linked by a 1, 1-glycosidic linkage, is widespread throughout the biology world. In some lower orders of plants and fungi, this disaccharide is mainly stored as a source for carbon and energy [1]. In the animal kingdom it is abundant and e.g. insects use it as a source for glucose to provide sufficient energy during flight [2]. In yeast and bacteria, it was reported that trehalose could protect cells from a variety of physical and chemical stresses, such as freezing, heat, desiccation, acidic conditions, and osmotic and oxidative stress $[3,4]$. Due to its desirable characteristics, it has been also applied as an additive, stabilizer and preservative to food, cosmetics, as well as medicinal and biological reagents [5].

At present, many trehalose synthesizing enzymes systems have been reported in microorganisms [6]. There are three pathways widely distributed among them: (1) Phosphatebased enzyme complex systems: Trehalose is synthesized through the transfer of the glucosyl moiety from UDP-glucose to glucose-1-phosphate, forming the intermediate 
trehalose-6-phosphate which was then hydrolyzed by phosphatase to yield free trehalose [7,8]. (2) A two-step enzyme system with maltooligosyl trehalose synthase (TreY) and maltooligosyl trehalose trehalohydrolase (TreZ) were found for trehalose biosynthesis in Arthrobacter sp. [9], Brevibacterium helvolum [10] and Bradyrhizobium [11]. (3) TreS synthesizing trehalose from maltose in one step was found only in bacteria [12]. We are most interested in TreS as a simple biocatalyst for trehalose production. Up to now, a few treS genes from different bacterial species have been reported to be cloned, expressed and characterized, including Pseudomonas stutzeri CJ38 [13], Pimelobacter sp. R48 [14], Mycobacterium smegmatis [15], Arthrobacter aurescens [16], Propionibacterium freudenreichii [17], Corynebacterium glutamicum ATCC13032 [18] and some thermophilic strains [19-21].

The Tibetan plateau is a high-altitude region where it can be assumed that bacteria are frequently exposed to stress conditions, such as cold, hypoxia, nutritional stress and high ultraviolet radiation. The microorganisms in this environment have received much interest because of their special properties [22]. Therefore, it is highly desirable to develop an effective strategy for isolation and subsequent screening of new Tres from the extreme environment

In this study, several TreS producing strains were screened from soil bacteria derived from the plateau soil sample by degenerate PCR based on the analysis of conserved domains. The full-length of the novel treS gene of Enterobacter hormaechei was obtained by thermal asymmetric interlaced PCR (TAIL-PCR). Subsequently, the gene was expressed in Escherichia coli (E. coli), and the recombinant TreS was purified and characterized.

\section{Results and discussion \\ Gene sequence analysis and strain screenings}

By multiple alignment analysis, the four highly conserved motifs HE/QPDLN, NHDELD/TLE, GIRRRLAP and YGDEIGMGD were found among protein sequences of TreS published at NCBI (Figure 1). The NHDELD/TLE domain (the DF2 primer region) had the feature of glycoside hydrolase $(\mathrm{GH})$ family 16 site, suggesting that the identified tres gene encoding products possibly had hydrolytic activity. In addition, there were some other motifs identified by sequence alignment with relatively lower homologies, including N/QHTSDQ/AH, GFRL/ ADA, VRTPMQW and GGFS (Figure 1).

Among the 86 bacterial strains isolated from the plateau soil sample, 6 different bacterial species were identified to be treS positive. Amplified core regions were sequenced and showed different similarity to relevant genes as summarized in Table 1 . This result provided evidence for the distribution of TreS producing bacteria in extreme environment.

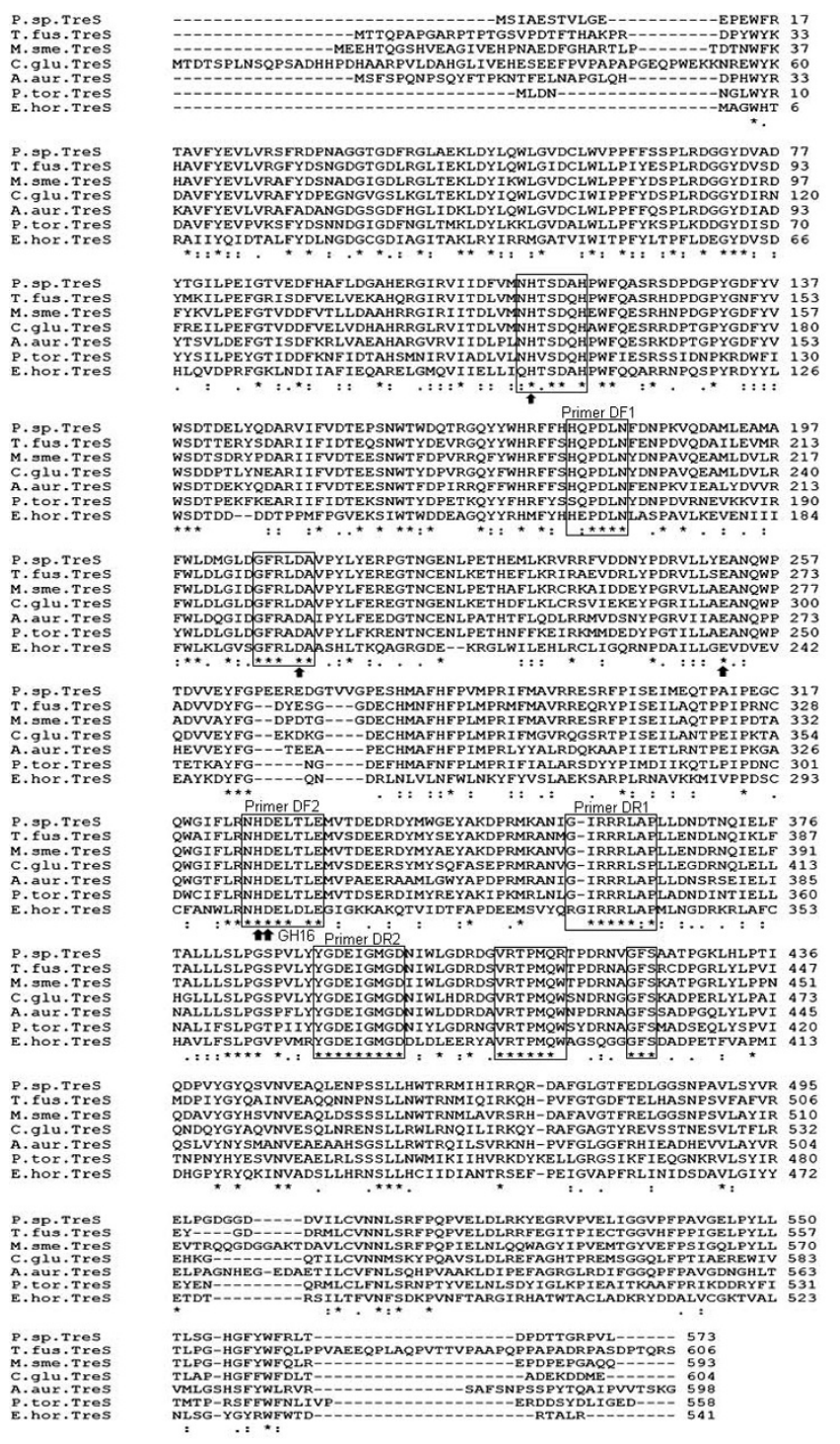

\section{Figure I}

Multiple sequence alignment of TreS. P.sp.TreS, Pimelobacter sp. R48 TreS (BAAII 303); T.fus.TreS, Thermobifida fusca TreS (AAZ54622); M.sme.TreS, Mycobacterium smegmatis TreS (ABK7I53I); C.glu.TreS, Corynebacterium glutamicum TreS (CAF20645); A.aur.TreS, Arthrobacter aurescens TreS (ACL80570); P.tor.TreS, Picrophius torridus TreS (AAT42654); E.hor.TreS, Enterobacter hormaechei TreS (FJ2 I5664). Conserved residues are in frames. GHI6 represents conserved domain of glycoside hydrolase family 16. Arrows indicate putative conserved active sites. Asterisks located under the alignment represent identity; colons represent strong characteristic similarity and periods represent similarity.

\section{Cloning of Enterobacter hormaechei treS gene and analysis}

A 228 bp core region of Enterobacter hormaechei treS gene was amplified by degenerate PCR. Its $3^{\prime}$ and $5^{\prime}$ flanking sequences were amplified by TAIL-PCR. By this a $1626 \mathrm{bp}$ open reading frame (ORF) sequence was obtained, encod- 
Table I: Strains identified by I6SrRNA and protein sequence identities

\begin{tabular}{|c|c|c|c|c|c|}
\hline \multirow[t]{2}{*}{ Strain name } & \multirow[t]{2}{*}{ Primer set } & \multirow[t]{2}{*}{ Amplified size (bp/aa) } & \multicolumn{3}{|c|}{ Blast result of core regions } \\
\hline & & & Protein identity & Compared bacterium & Genbank accession No. \\
\hline Enterobacter hormaechei & DF2 \& DR2 & $228 / 76$ & $69 \%$ & Klebsiella pneumoniae & СР000964 \\
\hline Enterobacter asburiae & DF2 \& DR2 & $228 / 76$ & $72 \%$ & Klebsiella pneumoniae & CP000964 \\
\hline Chryseobacterium sp. & DF2 \& DR2 & $225 / 75$ & $96 \%$ & Corynebacterium glutamicum & $\underline{\text { YP226546 }}$ \\
\hline Pseudomonas putida & DFI \& DRI & $444 / 148$ & $98 \%$ & Pseudomonas putida & ACA72320 \\
\hline Stenotrophomonas maltophilia & DFI \& DR2 & $642 / 214$ & $99 \%$ & Stenotrophomonas maltophilia & $\overline{C A Q 46113}$ \\
\hline Pseudomonas aeruginosa & DFI \& DR2 & $657 / 219$ & $95 \%$ & Pseudomonas fluorescens & $\overline{A A Y 92145}$ \\
\hline
\end{tabular}

ing 541 amino acids with a predicted molecular mass $\left(M_{\mathrm{r}}\right)$ of $61.8 \mathrm{kDa}$. As analyzed by NCBI BLAST, the full-length ORF of the Enterobacter hormaechei treS gene showed the highest similarity with several encoding sequences of TreS from Klebsiella pneumoniae 342 (CP000964, 815/1161, 70\%), Pseudomonas stutzeri A1501 (NC000304, 386/569, 67\%) and Pseudomonas aeruginosa PA7 (CP000744, 730/ $1119,65 \%)$.

All of the conserved regions mentioned above were found in Enterobacter hormaechei TreS (Figure 1). Besides the GH16 domain, other active sites of glycosidase (H...D...E...HD) were also observed in most bacterial TreS (Figure 1), as reported by Chen [20]. It is also reported that a glycosidase of Thermobifida fusca had TreS activity [21]. Therefore, it was suggested that TreS might employ a hydrolysis mechanism.

\section{Expression and purification of recombinant TreS}

The pET30a(+)-treS plasmid was transformed into the $E$. coli BL21 (DE3) plysS expression host, and cells were induced by isopropyl $\beta$-D-1-thiogalactopyranoside (IPTG). When compared to the sample without induction, only the induced cells containing the recombinant vector expressed an extra $65 \mathrm{kDa}$ protein (Figure 2). The recombinant protein was about $3 \mathrm{kDa}$ heavier than the predicted $\mathrm{M}_{\mathrm{r}}$ of $61.8 \mathrm{kDa}$, which was due to the additional 46 amino acids including the 6-His tag at the $\mathrm{N}^{\prime}$ terminus.

$67 \mathrm{mg}$ of recombinant TreS were purified from the supernatant of cell lysate containing $589 \mathrm{mg}$ of crude protein. Soluble recombinant protein was effectively purified at a yield of $11.4 \%(\mathrm{w} / \mathrm{w})$ of the total soluble protein. The final preparation showed a single band with an $M_{r}$ of approximately $65 \mathrm{kDa}$ (Figure 2).

\section{Activity assay of recombinant TreS and products assay of catalytic reaction}

TreS activity was detected with purified TreS in reactions of the conversion between maltose and trehalose. It was confirmed that the cloned fragment was the intrinsically coding sequence of active TreS. The highest activity was calculated to be $18.5 \mathrm{U} / \mathrm{mg}$. The activity value was lower than that of the recombinant TreS of Pseudomonas stutzeri CJ38 [13], but close to that of the recombinant TreS of Mycobacterium smegmatis [15].

The amount of glucose was also detected by ion chromatography (IC) (Figure 3) and shown to be consistent with the features of glycoside hydrolase as discussed above. Commonly, glucose is released in most of the conversion reactions of bacterial-derived TreS [14-21]. The small amount of glucose is generated under entry of a water molecule into the catalytic pocket to induce hydrolysis prior to formation of the glycosidic linkage [19]. Individually, TreS from Pseudomonas stutzeri CJ38 was the only one reported without generation of glucose as a byproduct [13]. We found relatively low homology between the two TreS from Enterobacter hormaechei and Pseudomonas stutzeri CJ38 (data not shown), indicating that there exists a structural difference in the functional role. Hence, in order to improve the efficiency of the major trehalose formation, the strategy to screen the enzyme without byproducts still remains to be further exploited.

\section{The effect of $\mathrm{pH}$ and temperature on recombinant TreS activity}

The conversion rate of recombinant TreS was constantly above $30 \%$ (equivalent to $65 \%$ of the maximal activity) at a broad pH range of 4 to 9, and reached the highest activity at $\mathrm{pH} 6$ (Figure 4A). The maximal conversion rate of $48 \%$ was observed at the optimum temperature of $37^{\circ} \mathrm{C}$ (Figure 4B). The optimum temperature was similar to that of Pseudomonas stutzeri CJ38 [13], Mycobacterium smegmatis [15], Arthrobacter aurescens [16] and Thermus caldophilus [23]. Although the conversion from maltose to trehalose could be accelerated at high temperatures (data not shown), Tres could produce more byproduct glucose when the temperature was increased $[21,23]$. Thus, it is probably more efficient to carry out conversions at moderate temperatures. In this report, the recombinant TreS showed a stable performance under the wide working 


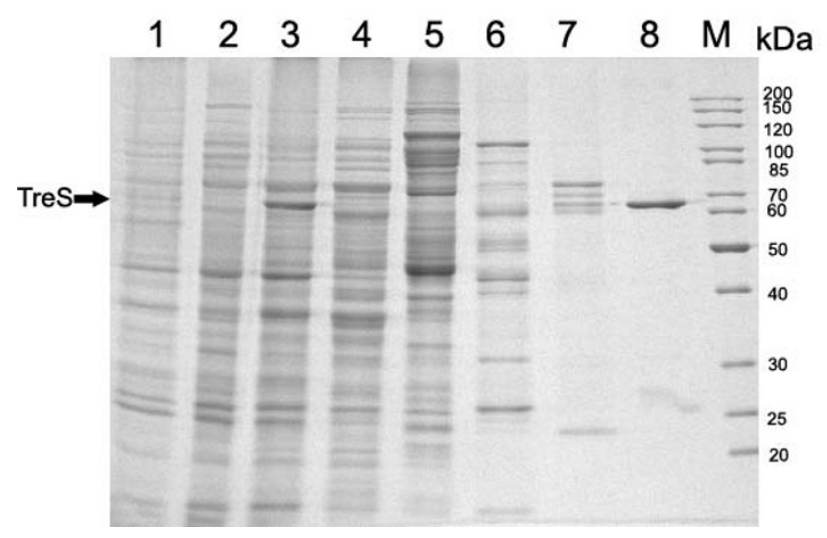

Figure 2

SDS-PAGE analysis of samples during TreS purification. All the protein samples were loaded onto a $12.5 \%$ polyacrylamide gel under denaturing conditions. The gel was stained with Coomassie Brilliant Blue R-250. The arrow indicates recombinant TreS. Lane I, control: Cell lysate of $E$. coli BL2I (DE3) plysS with pET30a(+); lane 2, cell lysate before induction; lane 3, cell lysate after induction; lane 4, flow through of the Ni-NTA column; lane 5, wash by $20 \mathrm{mM}$ imidazole; lane 6, wash by $40 \mathrm{mM}$ imidazole; lane 7, wash by 60 $\mathrm{mM}$ imidazole; lane 8, purified TreS; lane $M$, molecular weight marker (Bomaide, Beijing, China).

conditions ( $\mathrm{pH} 4-9$ and $20-55^{\circ} \mathrm{C}$, Figure 4). It suggested that the enzyme might be a candidate for trehalose production.

\section{The effects of metal ions and reagents on recombinant TreS activity}

Recombinant TreS activity could be influenced by several ions and reagents at different levels. The enzyme was strongly inhibited by $\mathrm{Hg}^{2+}, \mathrm{Zn}^{2+}$ and $\mathrm{Cu}^{2+}$ for more than $40 \%$ and by SDS for about $90 \%$. Other ions and chemical reagent, such as $\mathrm{Mg}^{2+}, \mathrm{Fe}^{2+}, \mathrm{Na}^{+}, \mathrm{NH}_{4}{ }^{+}$and EDTA, had no obvious effect, whereas $\mathrm{Ca}^{2+}$ and $\mathrm{Mn}^{2+}$ increased the activity slightly (Table 2). Besides, TreS was inactivated by addition of $\beta$-mercaptoethanol ( $\beta$-ME), which supports the hypothesis of a structural dependence on disulfidebonds.

\section{Kinetics of recombinant TreS activity}

The $K_{m}$ values for recombinant $E$. hormaechei TreS were found to be $25 \mathrm{mM}$ for maltose and $75 \mathrm{mM}$ for trehalose. $V_{\text {max }}$ values of $1.4 \mathrm{mM} / \mathrm{min} / \mathrm{mg}$ protein for maltose and $3.2 \mathrm{mM} / \mathrm{min} / \mathrm{mg}$ protein for trehalose were calculated, respectively. With regard to these results, the recombinant Tres had a higher affinity to maltose and a favorite reaction direction toward the synthesis of trehalose. Interestingly, all reported Tres enzymes share the feature of a reversible conversion at different degrees.

\section{Conclusion}

In summary, some TreS producing strains had been isolated from natural environment based on conserved domains and degenerate PCR. The treS gene from Enterobacter hormaechei was cloned by TAIL-PCR and expressed successfully. The characterization of the recombinant TreS suggested its potential application for trehalose production from maltose. Thus, the general applicability of this strategy for isolation of TreS producing strains and cloning of novel tres genes from natural sources was demonstrated.

\section{Methods}

Bacterial strains, media and culture conditions

Bacterial strains obtained from a Tibetan Plateau soil specimen were grown and enriched in nutrient broth medium (pepton $1 \% \mathrm{w} / \mathrm{v}$, beef extract $0.3 \% \mathrm{w} / \mathrm{v}, \mathrm{NaCl} 0.5 \% \mathrm{w} / \mathrm{v}$ ) at $30^{\circ} \mathrm{C}$ for 2 days. Arthrobacter aurescens, serving as a TreS positive control, was obtained from China General Microbiological Culture Collection Center (CGMCC1.1892).

E. coli Top10 was used for construction of recombinant plasmids. E. coli BL21 (DE3) plysS (Novagen, Germany) was used as expression host and grown in LB medium containing $50 \mu \mathrm{g} / \mathrm{ml}$ kanamycin (Kan) and $34 \mu \mathrm{g} / \mathrm{ml}$ chloramphenicol (Cam) after transformation.

\section{Gene sequence analysis and strain screenings}

All bacterial TreS sequences published in the NCBI Database were collected and analyzed by the multiple sequence alignment program CLUSTAL W2 http:// www.ebi.ac.uk/Tools/clustalw2. As shown in Figure 1, four degenerate primers (DF1, 2 and DR1, 2) were synthesized based on the conserved domains (see additional file 1 for the primer sequences).

DNA preparation of bacterial strains isolated from the soil specimen was performed by alkaline lysis [24]. Degenerate PCR was carried out according to the parameters optimized with the genome DNA template of Arthrobacter aurescens. PCR products were separated on a 1\% agarose gel, recovered by using a Gel Extraction Kit (Tiangen, Beijing, China), and sub-cloned into the pMD18-T vector (TaKaRa, DaLian, China) for sequence analysis (SunBio, Beijing, China). The sequenced fragments were analyzed by BLAST http://www.ncbi.nlm.nih.gov/BLAST. All isolated positive strains were subsequently identified by their 16SrRNA sequence.

\section{Cloning of the treS gene of Enterobacter hormaechei and} construction of the expression vector

TAIL-PCR was performed to amplify the 3' and 5' fragments of Enterobacter hormaechei treS. The PU and PD primers (see additional file 1) for TAIL-PCR were designed 


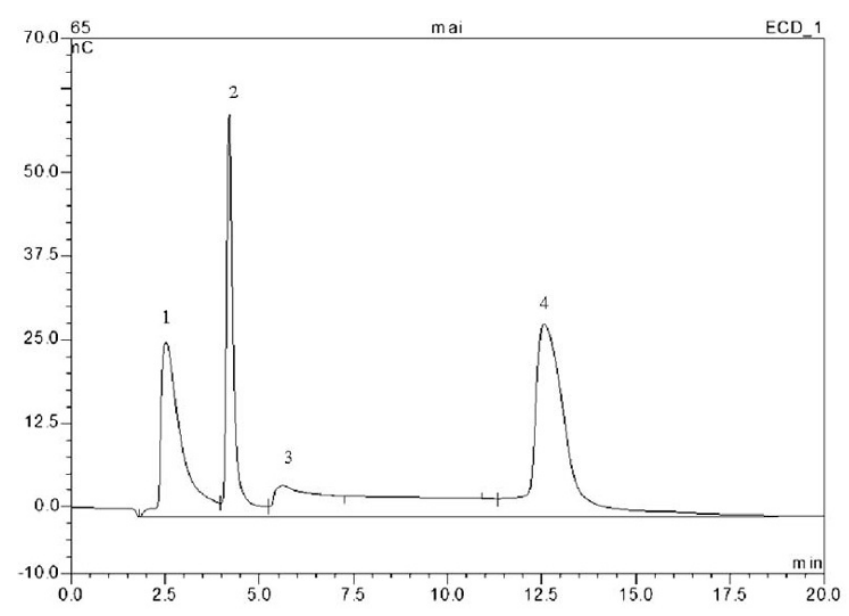

Figure 3

IC assay of reaction products. Reaction mixtures containing $400 \mu \mathrm{l}$ purified TreS solution and $100 \mu \mathrm{l}$ maltose (500 $\mathrm{mM})$ substrate in $50 \mathrm{mM}$ potassium phosphate buffer $(\mathrm{pH} 6)$ were incubated at $37^{\circ} \mathrm{C}$ for $2 \mathrm{~h}$. The reaction mixtures were subsequently analyzed by IC, as described in the "Methods" section. Peak I, trehalose; peak 2, glucose; peak 3, buffer reagent; peak 4, maltose.

and synthesized according to the core region amplified in degenerate PCR. The reaction parameters and the AD primers for TAIL-PCR were referred to previous reports $[25,26]$. The full length of treS was assembled from $3^{\prime}, 5^{\prime}$ fragments and the core region. The deduced amino acid sequence was analyzed by DNAMAN 1.0.

The TreSF and TreSR primers (see additional file 1) were synthesized to introduce Nco I and Not I sites into the 3' and 5' ends of treS ORF, respectively. The PCR product was digested by Nco I and Not I, and inserted into the same digested pET30a(+) vector (Novagen, Cat No. 69909-3, Darmstadt, Germany) to generate His-tagged pET30a(+)treS. The recombinant plasmid was confirmed by DNA sequencing and transformed to the E. coli BL21 (DE3) plysS.

\section{Protein expression and purification}

The E. coli BL21 (DE3) plysS transformed with pET30a(+)treS was cultured in LB medium containing $50 \mu \mathrm{g} / \mathrm{ml} \mathrm{Kan}$ and $34 \mu \mathrm{g} / \mathrm{ml} \mathrm{Cam}$ in a shaker at $220 \mathrm{rpm}$ and $37^{\circ} \mathrm{C}$ until an $\mathrm{OD}_{600}$ of 0.6 was reached. These cells were induced with a final concentration of $0.5 \mathrm{mM}$ IPTG and grown at $25^{\circ} \mathrm{C}$ for an addition of $4 \mathrm{~h}$. Cell extracts were analyzed by $12.5 \%(\mathrm{w} / \mathrm{w})$ SDS-polyacrylamide gel electrophoresis (SDS-PAGE). Gels with expressed protein were analyzed by a Molecular Imager ${ }^{\circledR}$ Gel DocTM XR system $170-8170$ (Bio-Rad, Hercules CA, USA) using the Quantity one4.6.3 1-D analysis software.
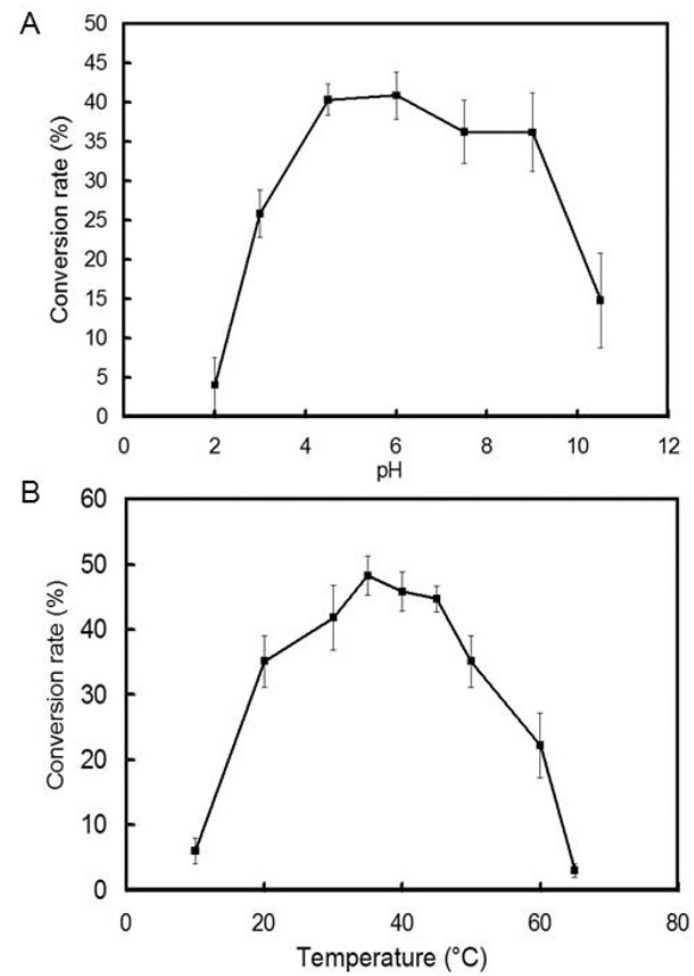

Figure 4

Effect of $\mathrm{pH}$ and temperature on TreS activity. (A) Effect of $\mathrm{pH}$ on TreS activity. The enzyme activity of TreS at various $\mathrm{pHs}$ was assayed at $37^{\circ} \mathrm{C}$ in $50 \mathrm{mM}$ potassium phosphate buffer ( $\mathrm{pH}$ 2-10.5) for $30 \mathrm{~min}$, using $100 \mathrm{mM}$ maltose as a substrate; (B) Effect of temperature on TreS activity. The enzyme activity of TreS at various temperatures was assayed in $50 \mathrm{mM}$ potassium phosphate buffer $(\mathrm{pH} 7)$ for $30 \mathrm{~min}$, using $100 \mathrm{mM}$ maltose as a substrate.

For purification, cells were harvested by centrifugation and resuspended in lysis buffer $\left(50 \mathrm{mM} \mathrm{KH_{2 } \mathrm { PO } _ { 4 ^ { - } }}\right.$ $\mathrm{K}_{2} \mathrm{HPO}_{4}, 500 \mathrm{mM} \mathrm{NaCl}, \mathrm{pH}$ 7.9) followed by sonification and centrifugation at $12,000 \times \mathrm{g}$ for $20 \mathrm{~min}$ at $4{ }^{\circ} \mathrm{C}$ to remove insoluble cell debris. The 6 -His tagged protein in supernatant fraction was purified by using a Ni-NTA affin-

Table 2: Effects of metal ions and chemicals on the activity of recombinant TreS

\begin{tabular}{llll}
\hline Reagent & Relative activity (\%) & Reagent & Relative activity (\%) \\
\hline $\mathrm{None}$ & $100^{*}$ & $\mathrm{Cu}^{2+}$ & $52 \pm 4.7$ \\
$\mathrm{Hg}^{2+}$ & $57 \pm 2.2$ & $\mathrm{Na}^{+}$ & $90 \pm 2.4$ \\
$\mathrm{Mg}^{2+}$ & $98 \pm 1.3$ & $\mathrm{NH}_{4}{ }^{+}$ & $101 \pm 4.3$ \\
$\mathrm{Ca}^{2+}$ & $103 \pm 7.9$ & $\mathrm{SDS}$ & $10 \pm 1.1$ \\
$\mathrm{Zn}^{2+}$ & $59 \pm 1.3$ & EDTA & $98 \pm 5.8$ \\
$\mathrm{Fe}^{2+}$ & $92 \pm 5.9$ & $\beta-M E$ & 0 \\
$\mathrm{Mn}^{2+}$ & $111 \pm 10.7$ & & \\
\hline
\end{tabular}

* The enzyme activity of TreS without the addition of ions or reagents was taken to be $100 \%$. 
ity chromatography column (NEB, Beijing, China). Protein concentrations were determined by the Bradford method using bovine serum albumin as a standard [27].

\section{Activity assay of recombinant TreS}

The catalytic reaction was performed in a mixture containing the TreS solution and $100 \mathrm{mM}$ maltose in $50 \mathrm{mM}$ phosphate buffer ( $\mathrm{pH} \mathrm{6)}$ at $37^{\circ} \mathrm{C}$ for $2 \mathrm{~h}$. Samples were taken at different time intervals during the reaction and boiled for $10 \mathrm{~min}$ to stop the reaction. The reaction mixtures were separated by thin layer chromatography on G60 TLC silica plates (Merck, Darmstadt, Germany) using a solvent system of 1-butanol/pyridine/water (4:5:1, v/v). Products released by TreS were quantified by IC using a Dionex2500 system equipped with a CarboPacPA ${ }^{\mathrm{TM}} 20$ column. One unit (U) of TreS was defined as the amount of enzyme required to produce $1 \mu \mathrm{mol}$ trehalose per min under the specified conditions [23]. The conversion rate was calculated by the ratio of the trehalose product to the amount of maltose substrate.

\section{Properties of recombinant TreS}

The optimum pH of TreS was assayed by incubating the purified enzyme with $100 \mathrm{mM}$ maltose substrate in 50 $\mathrm{mM}$ potassium phosphate buffer at $\mathrm{pH} 2$ to 10.5 and $37^{\circ} \mathrm{C}$ for $30 \mathrm{~min}$, respectively. The optimum temperature for TreS activity was determined at 10 to $60^{\circ} \mathrm{C}$ using the same buffer at $\mathrm{pH} 7$ for $30 \mathrm{~min}$, respectively. To determine the effect of metal ions and different chemical reagents on TreS, its activity was also assayed in the presence of these ions or compounds at $1 \mathrm{mM}$, respectively.

\section{Determination of kinetic parameters}

The Michaelis-Menten $\left(K_{m}\right)$ and maximum activity $\left(V_{\max }\right)$ constant for recombinant TreS were determined with different concentrations of substrates ranging from 1 to 200 $\mathrm{mM}$, and the data were plotted according to the Lineweaver and Burk method.

\section{Nucleotide sequence accession number}

The nucleotide sequence of Enterobacter hormaechei treS has been submitted to GenBank under accession no. FI215664.

\section{Competing interests}

The authors declare that they have no competing interests.

\section{Authors' contributions}

MY carried out gene cloning, expression, and characterization of the enzyme, and composed the manuscript. XLW carried out the isolation of strains from soil sample and the degenerate PCR optimization together with MY. WNG performed the TAIL-PCR with genomic DNA of isolated strains. HBD conceived and supervised the study. All authors have read and approved the final manuscript.

\section{Additional material}

\section{Additional file 1}

Primers used in this study. The nucleotide sequences of the primers used in this study.

Click here for file

[http://www.biomedcentral.com/content/supplementary/14752859-8-34-S1.doc]

\section{Acknowledgements}

We are grateful to Dr. Volker Jäger for his insightful comments and language improvement on the manuscript. This research was supported by a key project of the Chinese international science and technology cooperation program (Grant No.2005DFA3 1070) and the National 863 Program.

\section{References}

I. Thevelein JM: Regulation of trehalose mobilization in fungi. Microbiol Rev 1984, 48(I):42-59.

2. Chen Q, Haddad GG: Role of trehalose phosphate synthase and trehalose during hypoxia: from flies to mammals. J Exp Biol 2004, 207:3125-3129.

3. Leslie SB, Israeli E, Lighthart B, Crowe JH, Crowe LM: Trehalose and sucrose protect both membranes and proteins in intact bacteria during drying. Appl Environ Microbiol 1995, 6 I :3592-3597.

4. Wiemken A: Trehalose in yeast, stress protectant rather than reserve carbohydrate. Antonie van Leeuwenhoek 1990, 58:209-217.

5. Richards AB, Krakowka S, Dexter LB, Schmid H, Wolterbeek APM, Waalkens-Berendsen DH, Shigoyuki A, Kurimoto M: Trehalose: a review of properties, history of use and human tolerance, and results of multiple safety studies. Food Chem Toxicol 2002, 40:871-898.

6. Elbein AD, Pan YT, Pastuszak I, Carroll D: New insights on trehalose: a multifunctional molecule. Glycobiology 2003, I 3: I 7R-27R.

7. Van Vaeck C, Wera S, Van Dijck P, Thevelein JM: Analysis and modification of trehalose 6-phosphate levels in the yeast Saccharomyces cerevisiae with the use of Bacillus subtilis phosphotrehalase. Biochem / 200I, 353:157-162.

8. Pan YT, Carroll JD, Elbein AD: Trehalose-phosphate synthase of Mycobacterium tuberculosis: cloning, expression and properties of the recombinant enzyme. Eur I Biochem 2002, 269:6091-6100.

9. Yamamoto T, Maruta K, Watanabe H, Yamashita H, Kubota M, Fukuda S, Kurimoto M: Trehalose-producing operon treYZ from Arthrobacter ramosus S34. Biosci Biotechnol Biochem 200I, 65:1419-1423.

10. Kim YH, Kwon TK, Park S, Seo HS, Cheong JJ, Kim CH, Kim JK, Lee JS, Choi YD: Trehalose synthesis by sequential reactions of recombinant maltooligosyltrehalose synthase and maltooligosyltrehalose trehalohydrolase from Brevibacterium helvolum. Appl Environ Microbiol 2000, 66:4620-4624.

II. Streeter JG, Gomez ML: Three enzymes for trehalose synthesis in Bradyrhizobium cultured bacteria and in bacteroids from soybean nodules. Appl Environ Microbiol 2006, 72:4250-4255.

12. Avonce N, Mendoza-Vargas A, Morett E, Iturriaga G: Insights on the evolution of trehalose biosynthesis. BMC Evol Biol 2006, 6:109-123.

13. Lee JH, Lee KH, Kim CG, Lee SY, Kim GJ, Park YH, Chung SO: Cloning and expression of a trehalose synthase from Pseudomonas stutzeri CJ38 in Escherichia coli for the production of trehalose. Appl Microbiol Biotechnol 2005, 68:213-219.

14. Tsusaki K, Nishimoto T, Nakada T, Kubota M, Chaen H, Sugimoto T, Kurimoto $M$ : Cloning and sequencing of trehalose synthase gene from Pimelobacter sp. R48. Biochim Biophys Acta 1996, I 290: I-3.

15. Pan YT, Edavana VK, Jourdian WJ, Edmondson R, Carroll JD, Pastuszak I, Elbein AD: Trehalose synthase of Mycobacterium smegmatis: purification, cloning, expression, and properties of the enzyme. Eur J Biochem 2004, 27 I:4259-4269. 
16. Wu XL, Ding HB, Yue M, Qiao Y: Gene cloning, expression and characterization of a novel trehalose synthase from Arthrobacter aurescens. Appl Microbiol Biotechnol 2009, 83:477-482.

17. Cardoso FS, Castro RF, Borges N, Santos H: Biochemical and genetic characterization of the pathways for trehalose metabolism in Propionibacterium freudenreichii, and their role in stress response. Microbiology 2007, 153:270-280.

18. Wolf A, Kramer R, Morbach S: Three pathways for trehalose metabolism in Corynebacterium glutamicum ATCCI3032 and their significance in response to osmotic stress. Mol Microbiol 2003, 49: III9-1134.

19. Koh S, Kim J, Shin HJ, Lee DH, Bae J, Kim D, Lee DS: Mechanistic study of the intramolecular conversion of maltose to trehalose by Thermus caldophilus GK24 trehalose synthase. Carbohydr Res 2003, 338: I339-I343.

20. Chen YS, Lee GC, Shaw JF: Gene cloning, expression, and biochemical characterization of a recombinant trehalose synthase from Picrophius torridus in Escherichia coli. J Agric Food Chem 2006, 54:7098-7104.

21. Wei YT, Zhu QX, Luo ZF, Lu FS, Chen FZ, Wang QY, Huang K, Meng $J Z$, Wang R, Huang RB: Cloning, expression and identification of a new trehalose synthase gene from Thermobifida fusca genome. Acta Biochim Biophys Sin 2004, 36:477-484.

22. Zhang XJ, Ma XJ, Wang NL, Yao TD: New subgroup of Bacteroidetes and diverse microorganisms in Tibetan plateau glacial ice provide a biological record of environmental conditions. FEMS Microbiol Ecol 2009, 67:21-29.

23. Koh S, Shin HJ, Kim JS, Lee DS, Lee SY: Trehalose synthesis from maltose by a thermostable trehalose synthase from Thermus caldophilus. Biotechnol Lett 1998, 20:757-76I.

24. Sambrook J, Fritsch EF, Maniatis T: Molecular cloning: a laboratory manual New York: Cold Spring Harbor Press; 1989.

25. Liu YG, Huang N: Efficient amplification of insert end sequences from bacterial artificial chromosome clones by thermal asymmetric interlaced PCR. Plant Mol Biol Rep 1998, 16(2): 175-181.

26. Liu YG, Mitsukawa N, Oosumi T, Whittier RF: Efficient isolation and mapping of Arabidopsis thaliana T-DNA insert junctions by thermal asymmetric interlaced PCR. Plant J 1995, 8:457-463.

27. Walker JM, (Ed): The Protein Protocols Handbook 2nd edition. New Jersey: Humana Press Inc., Totowa; 2002.

Publish with Bio Med Central and every scientist can read your work free of charge

"BioMed Central will be the most significant development for disseminating the results of biomedical research in our lifetime. "

Sir Paul Nurse, Cancer Research UK

Your research papers will be:

- available free of charge to the entire biomedical community

- peer reviewed and published immediately upon acceptance

- cited in PubMed and archived on PubMed Central

- yours - you keep the copyright
BioMedcentral 